\title{
China's Grain Trade Research Based on DEA model of National Food Security Perspective: Soybean as an Example
}

\author{
Jianting FU*, Dan LYU, Jian SUN
}

\begin{abstract}
Food is a special commodity that is related to the national economy and people's livelihood and has strategic significance. It is an important factor in the national security strategy. Therefore, grain trade not only has the strategic characteristics of safeguarding national economic security, but also has the strategic characteristics of stabilizing national political security. At present, Chinese three main staples, rice, corn, and wheat are self-sufficient. However, Chinese soybean production has declined rapidly, and its external dependence has increased significantly. It is the most vulnerable part of the national food security strategy. This paper proposes the DEA model to analyze the soybean situation in China. The current situation of Chinese soybean production and supply can no longer guarantee the realization of the first specific goal of food security. Chinese soybeans are highly dependent on the international market, and China has no pricing power. Chinese soybean problem may bring a food crisis under the invisible control of big countries. In view of the new characteristics of Sino-US relations and the long-term nature of Sino-US competition and cooperation in the near future, it is necessary for China to examine the impact that soybeans may have on national food security. China needs to make an early plan to deal with the possible soybean crisis.
\end{abstract}

Keywords: food security; grain trade; international market; national security strategy; soybean trade

\section{INTRODUCTION}

At present, the global resource and population matching through global trade is an inevitable path, and food trade is no exception. Free world food trade has an irreplaceable significance for safeguarding world food security, promoting agricultural prosperity and development of all countries, and improving people's living standards and quality. Faced with the new situation of world food production and trade, it is urgent to deepen global food trade cooperation. Over the past 40 years of reform and opening up, China's agricultural development has achieved great achievements that have attracted worldwide attention, and national food security has been effectively guaranteed [1]. Food production increased from more than 600 billion kilograms in 1978 to $1,235.8$ billion kilograms in 2017, and has exceeded 1.2 trillion kilograms for many years. The main food crops such as rice, wheat, and soybean are self-sufficient, and the output of meat, eggs, vegetables, fruits and fish ranks first. At this stage, China's three main staples of wheat, rice, and soybean have problems of phased oversupply and insufficient supply. China has adjusted its grain supply structure to improve grain quality and meet the increasing demand for consumer consumption. The country relies on its own strength to solve the problem of eating of more than 1.3 billion people. This is China's important contribution to global food security [2]. However, China's resource endowment also determines that by relying on domestic resources it is difficult to solve all agricultural and food needs, and making full use of both domestic and international markets and resources is an inevitable choice for solving China's food problems.

Especially since China joined the World Trade Organization, the level of China's agricultural opening up has continuously improved, and the scale of agricultural trade has grown rapidly. From 2001 to 2017, the total import and export trade of agricultural products increased from US 27.92 billion to US 201.39 billion, an average annual increase of $13.1 \%$ [3]. It has become the world's second largest agricultural trade country, accounting for $6 \%$ of global agricultural trade. Imports of bulk agricultural products such as grain, cotton, oil and sugar have increased domestic effective supply, slowed down resource pressures, met consumer demand, and exported agricultural products such as vegetables, fruits and aquatic products, and promoted agricultural value-added efficiency and farmers' income. Over the years, China has insisted on promoting trade liberalization.

The average tariff rate of agricultural products has reduced from $46.6 \%$ in 1992 to $15.2 \%$. It is one of the countries with the lowest level of tariffs and the highest degree of trade liberalization in the world. In 2015, Chinese soybean imports reached a record hight of 81.69 million tons. At that time, more than $60 \%$ of global soybean exports flowed into China. The rapid growth of imports reflects the high dependence of the Chinese soybean industry on the international market. As of 2015, $88 \%$ of Chinese soybean consumption is dependent on imports. In the past two decades, the Chinese soybean industry has undergone earth-shaking changes. Soybean demand is in short supply and imports are huge. However, the scale of soybean cultivation has been decreasing over the past decade [4]. In the mid-20th century, Chinese soybean acreage exceeded 10,000 thousand hectares. China has become one of the world's major soybean growers. However, in the past decade, soybean acreage has fallen rapidly. It fell from 9,304 thousand hectares in 2006 to 7,202 thousand hectares in 2016, a drop of nearly a quarter. In the early $1990 \mathrm{~s}$, Chinese soybean consumption accounted for only $10 \%$ of global soybean production [5]. Today, China consumes nearly $30 \%$ of the world's soybeans. At the same time, China adheres to the promotion of trade and investment integration, adheres to multilateral agricultural exchanges and cooperation, continuously establishes, deepens and improves agricultural cooperation mechanisms, develops agricultural aid systems, and actively promotes agricultural production capacity and food security in developing countries.

With so much demand, why is Chinese soybean acreage decreasing year by year? Chinese soybean 
consumption has grown from being self-sufficient to highly dependent on the international market, and has maintained rapid growth in both absolute and relative imports. How can this flip-flop change be realized? At the same time, why is the Chinese soybean market highly dependent on the international market? Academic scholars usually explain it from the perspective of soybean trade. The author believes that the change of Chinese soybean import and export trade is not only a trade war, but also reflects the political game between big powers under the economic cloak [6]. This article attempts to clarify the reasons for the changes in Chinese soybean import and export trade, and to demonstrate the US's invisible control in Chinese soybean imports. This paper attempts to provide policy recommendations for enhancing Chinese food security by exploring possible future development opportunities for Chinese soybeans. Under the background of tight domestic food supply and demand balance and quality and safety standards, food and beverage trade is an important part of China's agricultural products trade, and international trade is an increasingly important part of China's food security system.

\section{INSPECTION CONTENT AND RELATED METHODS \\ 2.1 Analytical Framework for Determinants of Food Imports}

The deeper the dependence on food imports, the greater the food supply is constrained by the international market, and the greater the risk of uncertainty in food security. Therefore, any country will strive to achieve a certain degree of food self-sufficiency [7]. The availability and quantity of its food imports mainly depends on whether there are gaps and gaps in domestic supply and demand. The discussion of the motivation of food import should be cut from supply and demand, and the factors that determine the domestic supply and demand of food are the decisive factors for food import (Liu, Hussain, Zheng, Peng, Huang, $\&$ Cui, 2015). From the perspective of demand, population and economic development levels are the most important factors.

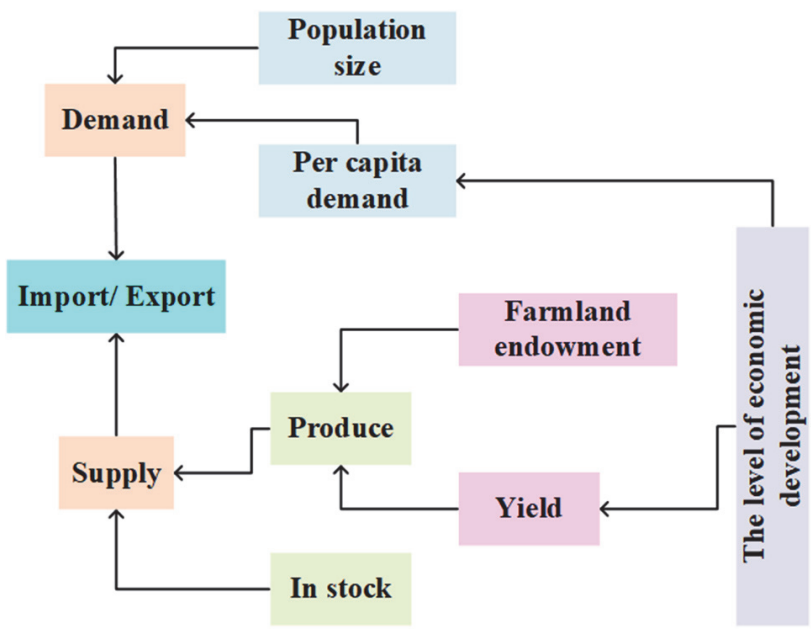

Figure 1 Food trade demand and supply framework

From the perspective of supply, domestic supply of grain consists of production and stocks, of which production is determined by cultivated endowment and yield, while the latter is closely related to the level of economic development. The main factors affecting food imports can be summarized as four levels of economic development level, population size, farmland endowment, and stocks in Fig. 1. Economic development will not only change the quantity and structure of food demand, but also it will change the production capacity of food, so the impact on food imports is complex. On the one hand, the process of economic development accompanied by a shift in the source of nutrition from grain-based to animal-based dietary structure, in which ration consumption will decline, but increased consumption of livestock products will lead to rapid growth in feed consumption, making food Total consumption has increased significantly. After entering the affluent stage, food consumption is gradually saturated, and the response of food consumption to income increase is no longer obvious. Curve fitting of per capita GDP and food demand found that food demand growth has stagnated after per capita GDP exceeds $\$ 30,000$. It can be seen that economic growth has a non-linear positive impact on food demand [8]. Therefore, the level of economic development is higher; the food productivity tends to be higher. Curve fitting of per capita GDP and grain yields showed a significant positive correlation. In terms of stimulating demand, economic growth has a positive effect on food imports. In terms of productivity, economic growth has a negative effect on food imports. The final impact of economic growth on food imports depends on the net effect of the superposition of these two effects. If the positive effect is greater than the negative effect, economic growth increases food imports. If the positive effect is less than the negative effect, economic growth reduces food imports. The population is the most basic factor in determining the scale of demand for food and its derivatives. The more people there are, the more food is consumed directly and indirectly, and population growth can bring about almost the same proportion of demand growth, thus having a positive effect on imports. Cultivated land is the most basic and irreplaceable food production material [9]. The more abundant the cultivated land resources, the stronger the ability to meet the demand by relying on their own production, and thus the importation. At the beginning of the period, stocks are part of the domestic food supply. Because of the high cost of holding stocks, when production cannot meet the demand, it will give priority to releasing stocks instead of increasing imports to stabilize market supply. In theory, the inventory level at the beginning of the period is higher, and it is more capable to stabilize imports.

\subsection{Chinese Soybean Planting and Import and Export Changes}

In general, the scale of domestic planting will increase or at least remain stable due to the rapid growth in demand for bulk agricultural products. The soybean planting area is difficult to grow based on the contradiction between the basic national conditions of the Chinese people and the rise of new agriculture. At the same time, Chinese soybean planting area has changed little in the past two decades, maintaining a floating around $15 \%$. However, the improvement of state subsidy policies will likely further stabilize soybean production. The new subsidy policy has 
indeed worked, but the flaws remain clear. Soybean acreage did not return to its original position after falling [10]. Two factors have led to a reduction in the size of soybean cultivation: low-margin and affordable imports of soybeans. There are two sources of soybean profit: planting profits and government subsidies. In China, the profit of soybean cultivation is not high, and the government subsidy system is not perfect. These cause the peasant farmers to be less motivated, which leads to a decline in planting scale. Compared with Chinese four major grain profits in Fig. 2, the profit from planting soybeans is the lowest, and it is decreasing year by year. Comparing the actual profit of the main food crops, from 2010 to 2018, the average paddy rice was 539 Yuan/mu, followed by corn at 433 Yuan/mu, and wheat by 335 Yuan/mu. The actual profit from planting soybeans is the lowest, averaging only $280 \mathrm{Yuan} / \mathrm{mu}$. Especially in recent years, the actual profit of soybeans has declined rapidly. The actual profit of soybean planting in 2014 was 435 Yuan/mu. In 2018, its actual profit dropped to $164 \mathrm{Yuan} / \mathrm{mu}$, which is only the 2000 income level in Fig. 2. This also explains why the net profit of corn has fallen or even surpassed soybeans in recent years, but the planting area has not decreased.

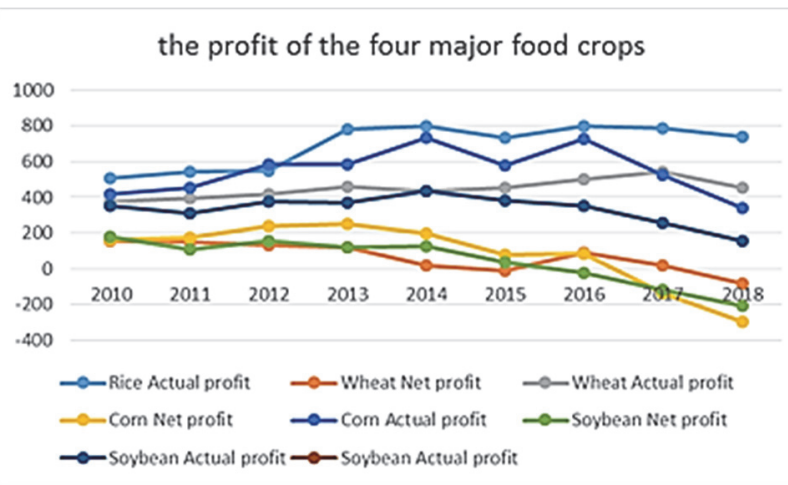

Figure 2 Changes in the profit of the four major food crops (2010 - 2018) (Unit: $\mathrm{RMB} / \mathrm{mu}$ )

China's soybean production area is mainly in Heilongjiang, and the total output accounts for more than one third of the country. The rapid growth in demand has led to rapid growth in world soybean production. The US Department of Agriculture predicted in April that the world soybean production in 2019/20 would reach 359 million tons. The world's major soybean producers are the United States, Brazil, Argentina, and China. Soybeans grown in the United States and Argentina are modified, and soybeans grown in Brazil and China are non-GM. China's soybean import and export trade is mainly based on soybean import trade and supplemented by export trade. From 2012 to 2017, soybean exports accounted for only $0.54 \%, 0.33 \%, 0.29 \%, 0.16 \%, 0.16 \%$, and $0.12 \%$ of the total soybean imports. Soybean imports increased from 59.38 million tons in 2012 to 95.54 million tons in 2017 , an average annual increase of $9.98 \%$. Soybean exports fell from 320,000 tons in 2012 to 110,000 tons, with an average annual decline of $19.23 \%$. From 2012 to 2017, China's soybean imports increased from 34.88 billion US\$ to 39.638 billion US\$, with an average annual growth rate of $2.53 \%$, and reached a peak of $\$ 40.085$ billion in 2014 . In contrast, soybean exports from 2012 to 2017 fell from \$ 279 million to \$ 91 million, with an average annual decline of $20.07 \%$. Taking the unit price of soybeans in China and the United States as an example, the average unit price of US soybeans in 2010 - 2018 was 2.12 Yuan $/ \mathrm{kg}$, and the unit price of Chinese soybeans was 3.42 Yuan $/ \mathrm{kg}$ [11]. The average unit price of Chinese soybeans is 1.6 times that of the United States (see Fig. 3). Chinese soybean unit price is still showing a downward trend in the case of cost increase, and soybean farmers are already unprofitable. However, soybeans are at a disadvantage in the international market due to high prices, and the situation of soybean farmers is even more difficult.

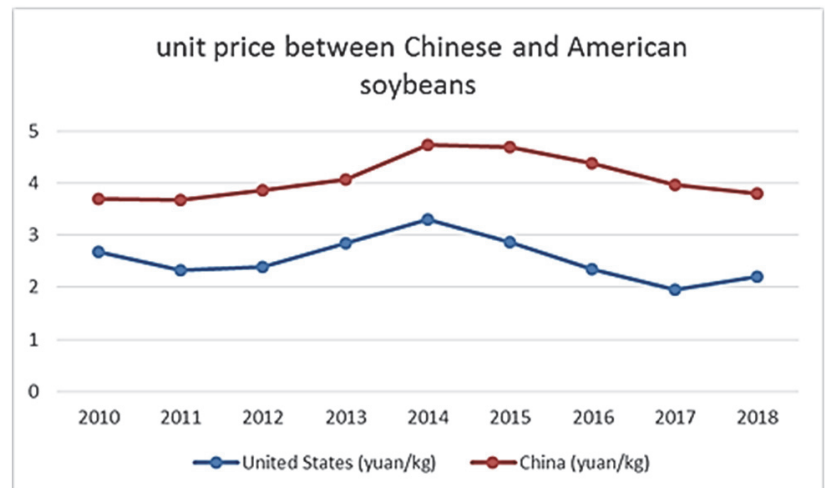

Figure 3 Comparison of unit price between Chinese and American soybeans (2010 - 2018)

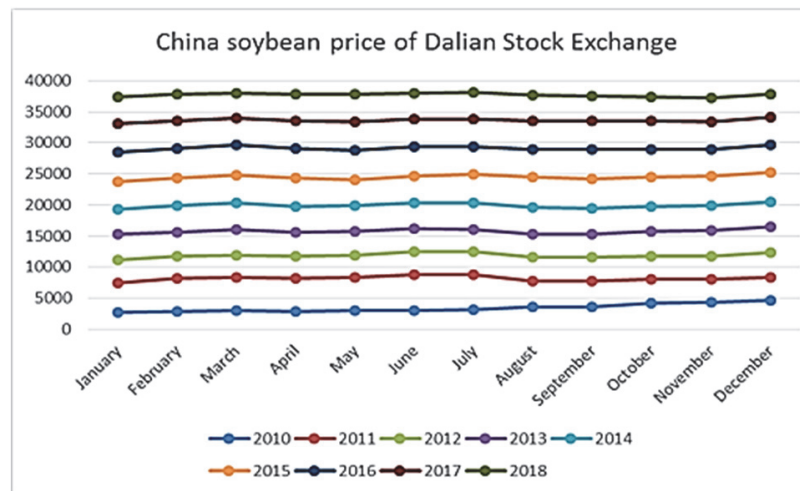

Figure 4 China soybean price of Dalian Stock Exchange (unit: Yuan/ton)

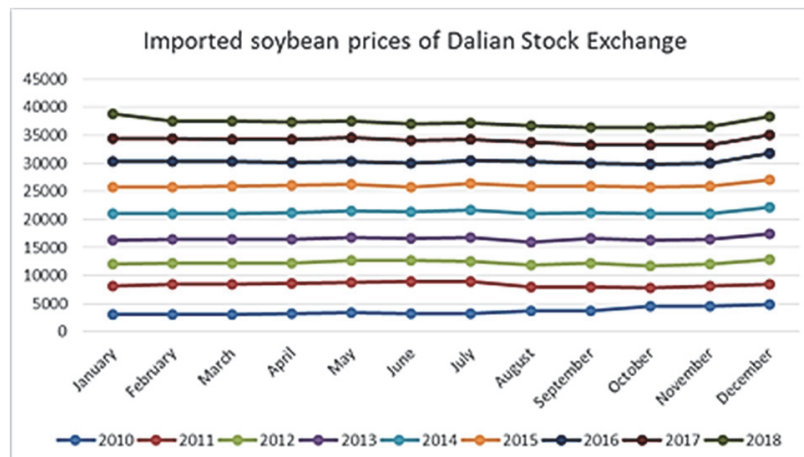

Figure 5 Imported soybean prices of Dalian Stock Exchange (unit: Yuan/ton)

Obviously, national policy is an important factor affecting the scale of soybean cultivation. In 2010 - 2014, due to the state's temporary storage policy for soybeans and the impact of imported soybeans, soybean acreage has been falling. In 2015 - 2018, the soybean subsidy policy was initially effective, and the scale of soybean cultivation remained stable. However, the country has not formed a long-term, stable soybean subsidy policy, which will still affect the enthusiasm of soybean farmers. In 2014, the 
average price per ton of domestic soybeans was about 766 Yuan higher than that of imported soybeans. In 2015, it reached a record hight, with an average of about 1,000 Yuan per ton of imported soybeans (in Fig. 5 and Fig. 4). Chinese soybean prices continue to rise.

\section{CHINA'S GRAIN TRADE RESEARCH BASED ON NATIONAL FOOD SECURITY PERSPECTIVE 3.1 Data Sources}

Data Sources and Standardization Processing Data from the China Rural Statistical Yearbook 2010 - 2018 and the China Statistical Yearbook were selected. In the grain circulation, the relevant data from 2010 to 2018 were selected from the China Food Yearbook for evaluation research. With the increase of residents' consumption level, the consumption structure of residents has changed, and the grain consumption has shown a decreasing trend, that is, the grain consumption is a reverse index.

Therefore, this study uses the DEA model to evaluate soybean food security. In 2010, it exceeded $20 \%$ for the first time and then grew rapidly. By 2013, Chinese soybean imports accounted for more than $60 \%$ of the world's total soybean exports. China has become the world's largest import soybean country. Chinese soybean imports are huge. At present, more than $90 \%$ of Chinese soybean imports are concentrated in the United States, Brazil, and Argentina [13]. The United States controls more than $90 \%$ of soybean production in Brazil and Argentina through genetically modified technology. By controlling Chinese soybean pricing and trade of multinational companies, the United States has almost invisibly controlled Chinese entire soybean industry.

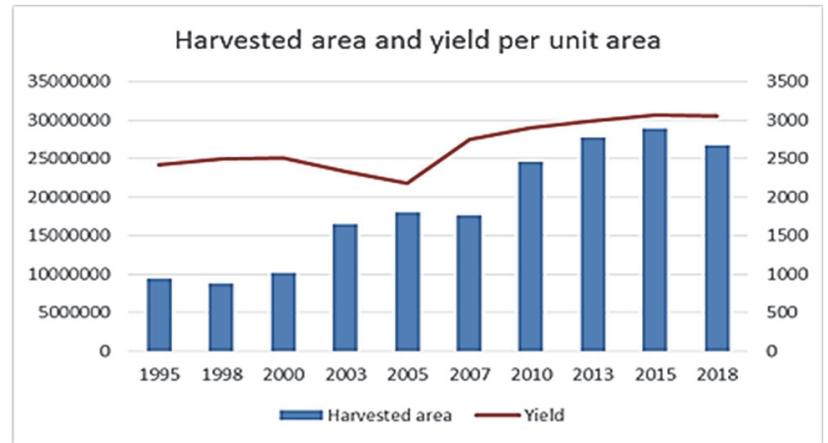

Figure 6 Harvested area and yield per unit area of Brazilian soybean

The $21^{\text {st }}$ century is a stage of rapid development, as shown in Fig. 6. In 2010, Brazil harvested 23.36 million hectares. By 2014, Brazil's soybean harvested area reached 30.27 million hectares, which is only less than the 33.4 million hectares in the United States. In the fifteen years from 2000 to 2014, Brazil's soybean harvested area increased by nearly 17 million hectares, and yields nearly doubled. Compared to the United States and Brazil, Argentina's soybean cultivation started late. From the perspective of harvested area, Argentina's soybean development was slow before the early 1990s. In 1993, the first harvested area of soybeans exceeded 5 million hectares. From the mid-1990s to 2005, it experienced a period of rapid growth. In 2005, Argentina's soybean harvest area reached 14 million hectares, and the harvested area doubled in 15 years. The period from 2006 to 2016 is a period of steady growth. By 2018, Argentina's soybean harvested area reached 19.5 million hectares, which is only less than the United States and Brazil. In terms of the volume of imports and exports, the total amount of soybeans imported by China has exceeded $60 \%$ of the world's total exports. China plays an important role in the international soybean trade. Although the trading share is huge, China still has no pricing power for soybeans. The price of Chinese soybeans is not the same as the price of soybeans on the Chicago Mercantile Exchange in Fig. 7. For soybean growers like the US, that would be a huge impact if China had soybean pricing power. Chinese lack of pricing power in the international soybean market will directly lead to the manipulation of Chinese soybean prices by the international market. Especially after joining the WTO, the price of Chinese soybeans and the price of international soybeans remain highly consistent. The control of Chinese soybean prices the profitability of big countries.

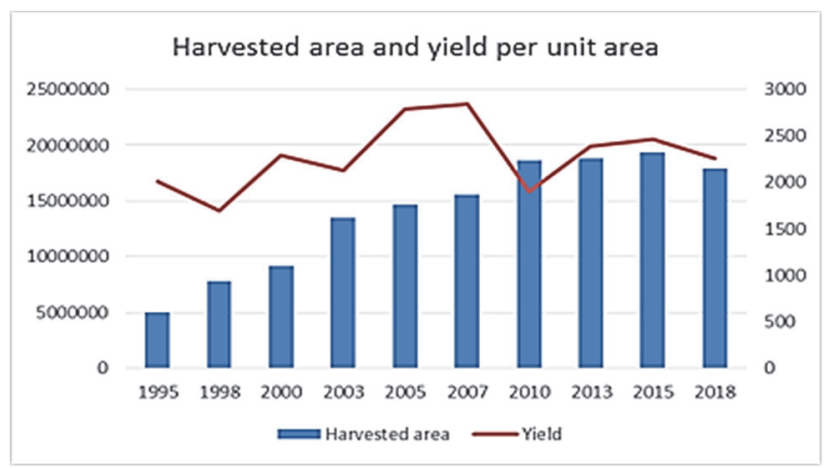

Figure 7 Harvested area and yield per unit area of Argentine soybean

The export of soybean is mainly concentrated in the United States, Brazil, Argentina, Paraguay, the Netherlands, India and other countries.

From 1995 to 2018, the exports of these six countries accounted for $86 \%$ of the world's total exports. Among them, the United States, Brazil, and Argentina have been the top three export markets for soybean products in the world. From 2012 to 2018, China's soybean production was 21.81 million tons, 22.75 million tons, 23.85 million tons, 25.51 million tons, 21.85 million tons and 20.3 million tons respectively. From this group of data, China's soybean production is far from meeting daily consumption. From 2012 to 2017, China's soybean import dependence was $83.2 \%, 83.2 \%, 83.8 \%, 88.6 \%, 86.6 \%$ and $86.2 \%$, respectively. Soybean import dependence is so high. On the one hand, it shows China's soybean consumption (bean product production). Soybean phospholipids, soy crushing, etc. are very large, and on the other hand, it has indirectly proved that China's soybean production is seriously insufficient.

\subsection{Grain Security Assurance Capacity Based on DEA Model}

This paper uses DEASOLVER Pro6 to carry out DEA analysis on the input and output indicators of grain production, circulation, and consumption, and obtains the evaluation results of China's soybean trade security. When the number of decision-making units is too small, the performance evaluation using the DEA method is prone to 
the situation where most decision-making units are effective but cannot perform DEA analysis. Since the national food security concerns are mostly concentrated in the grain production process, there is less concern about the grain circulation, which is resulting in the lack of statistical data and is related to the national grain industry. Therefore, in order to avoid the above reasons, it is impossible to carry out DEA analysis. This study uses the super-efficiency DEA model to evaluate the performance of China's food security. The basic model of super-efficient DEA is as follows. This article assumes that there are Decision Making Units, each of which has an "input" (indicating soy input) and an "output" (indicating the amount of "effectiveness" after the unit has consumed "soy". The relationship is shown in Fig. 1.
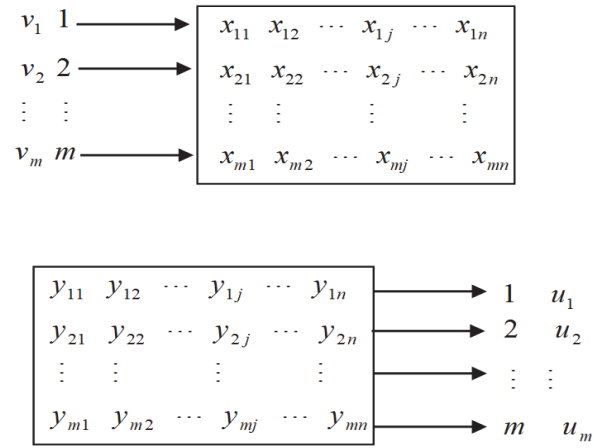

Figure 8 Trade security of soybean by DEA

$x_{i j}$ indicates the amount of input $i$ from the DMU to the input, $x_{i j}>0$;

$y_{i j}$ indicates the amount of input $j$ from the DMU to the input, $y_{i j}>0$;

$v_{i j}$ represents a measure (or "right") to the input in $I$;

$u_{i j}$ represents a measure (or "right") to the output of $r$; $i=1,2, \ldots, m ; j=1,2, \ldots, n ; r=1,2, \ldots, s$;

$x_{i j}$ and $y_{i j}$ are known data, which can be obtained from historical data. $v_{i}$ and $u_{r}$ are variables, corresponding to weight coefficients $\quad v=\left(v_{1}, v_{2}, \ldots, v_{m}\right)^{\mathrm{T}}$, $u=\left(u_{1}, u_{2}, \ldots, u_{m}\right)^{\mathrm{T}}$. Each decision unit has a corresponding efficiency evaluation index.

$$
h_{j}=\frac{\sum_{r=1}^{s} u_{r} y_{r j}}{\sum_{i=1}^{m} v_{r} x_{i j}}, j=1,2, \ldots, n
$$

The level of economic development is the most important factor affecting China's food imports, because the level of economic development is changing much faster than other factors. In 2015, per capita GDP based on constant prices was about 20 times that of 1978. It is always possible to appropriately select the coefficient $v$ and $u$, which satisfy with $h_{j} \leq 1, j=1,2, \ldots, n$. The first $j_{0}$ of DMU is now evaluated for security. Taking the weight coefficient $v$ and the variable $u$, the efficiency index of the $j_{0}$ DMU is the target, and the efficiency index $h_{j} \leq 1, j=1,2, \ldots, n$ of all DMUs is the monthly element, which constitutes the following optimization model $\left(C^{2} R\right.$ model).

$$
\left(C^{2} R\right)\left\{\begin{array}{l}
\sum_{r=1}^{s} u_{r} y_{r j_{0}} \\
\max \frac{\sum_{r=1}^{m} v_{i} x_{i j}}{\sum_{r} y_{r j}} \leq 1, j=1,2, \ldots, n \\
\frac{\sum_{i=1}^{m} v_{i} x_{i j}}{v=\left(v_{1}, v_{2}, \ldots, v_{m}\right)^{\mathrm{T}} \geq 0} \\
u=\left(u_{1}, u_{2}, \ldots, u_{m}\right)^{\mathrm{T}} \geq 0
\end{array}\right.
$$

From the demand point of view, the level of ration consumption has declined, but the upgrading of the dietary structure of more animal products continues to occur. In the past 10 years, per capita meat consumption has maintained an average annual growth rate of 3\%, resulting in a sudden increase in total food demand. In 2012 - 2016, the average annual growth rate of grain yield was $0.7 \%$, which was $60 \%$ lower than in the previous five years. In 2015, China's per capita GDP was only $\$ 4,069$, which is still far from the turning point of decoupling between food imports and economic growth. It is foreseeable that economic growth will continue to be a core factor driving the rise in food imports in the coming period. It is not difficult to see that using the above model to evaluate the $j_{0}$ DMU is not effective, but rather relative to all other decision units. The practical matrix symbol describes the above optimization model.

$(P)\left\{\begin{array}{l}\max \frac{u^{T} y_{j_{0}}}{v^{T} x_{j_{0}}}=V_{P} \\ \frac{u^{T} y_{j}}{v^{T} x_{j}} \leq 1, j=1,2, \ldots, n \\ v \geq 0, u \geq 0\end{array}\right.$

Use the Charnes-Cooper transform to turn fractional planning into the following points.

$(P)\left\{\begin{array}{l}\max \mu^{T} y_{j_{0}}=V_{P} \\ w^{T} x_{j}-\mu^{T} y_{j} \geq 0(j=1,2, \ldots, n) \\ w^{T} x_{j_{0}}=1 \\ w \geq 0, \mu \geq 0\end{array}\right.$

The dual programming of linear programming $(P)$ is as follows.

Definition: If the linear programming $(P)$ has an optimal solution $w^{0}>0, \mu^{0}>0$ and the optimal value $V_{P}=1$, then the decision unit $j_{0}$ is called the DEA model [14]. The duality theorem of linear programming knows that when the optimal value of dual linear programming $(D)$ is 1 , the optimal value of linear programming $(P)$ is also 1 . 
It can be seen that dual linear programming can be used to judge the DEA validity of the decision unit $j_{0}$.

$$
\text { (D) }\left\{\begin{array}{l}
\min \theta=V_{D} \\
\sum_{j=1}^{n} x_{j} \lambda_{j}+s^{-}=\theta x_{j_{0}} \\
\sum^{n} y_{j} \lambda_{j}-s^{+}=y_{j_{0}} \\
\lambda_{j} \geq 0(j=1,2, \ldots, n) \\
s^{+} \geq 0 s^{-} \geq 0
\end{array}\right.
$$

This paper selects the US, Brazil, and Argentina data on China's export trade as the research basis in Fig. 9, their proportion in combination with the DEA model is analyzed, and the stability of China's soybean trade given. The soybean prices of the two companies are compared in 2016 - 2018. In 2016, the average monthly price of soybeans on the Chicago Mercantile Exchange was $502.5 \$ /$ ton, equivalent to 3114.3 Yuan/ton. The average monthly price of imported soybeans on the Dalian Commodity Exchange was 4276.1 Yuan/ton, which was higher than the Chicago Mercantile Exchange by 1161.8 Yuan/ton. In 2017, the average price of soybeans on the Chicago Mercantile Exchange was 430.3 \$/ton, equivalent to 2643.4 Yuan/ton. The average monthly price of imported soybeans on the Dalian Commodity Exchange was 3715.7 Yuan/ton, which was 1072.3 Yuan higher per ton than the Chicago Mercantile Exchange. In 2018, the average monthly price of soybeans on the Chicago Mercantile Exchange was $346.2 \$ /$ ton, equivalent to 2153.6 Yuan/ton. The average monthly price of imported soybeans on the Dalian Commodity Exchange was 3096.8 Yuan/ton, which was higher than the Chicago Mercantile Exchange by 943.2 Yuan per ton.

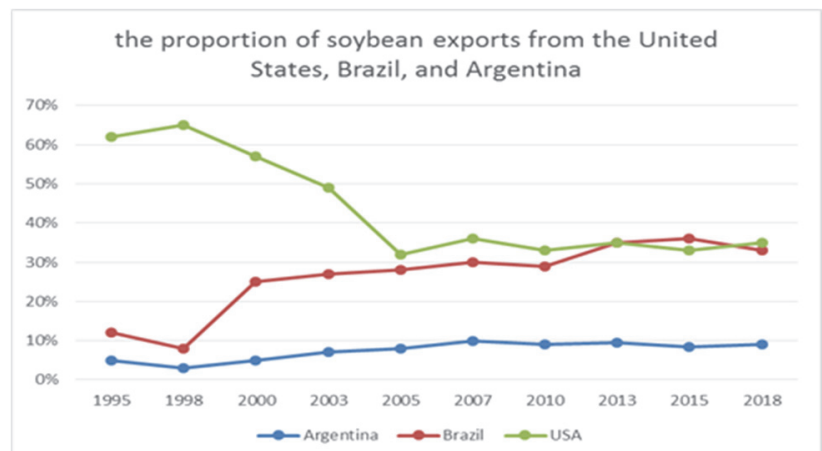

Figure 9 Changes in the proportion of soybean exports from the United States, Brazil, and Argentina to world exports

From the perspective of the proportion of grain imports and exports, the input and output of China's food security guarantees are relatively matched from 2010 to 2018 . The United States, Brazil, and Argentina all have soybean trade, and tend to change dynamically. It can be seen that China's 2010 - 2018 food security guarantees are more efficient. Although the trading share is huge, China still has no pricing power for soybeans. The price of Chinese soybeans is not the same as the price of soybeans on the Chicago Mercantile Exchange. For soybean growers like the US, that would be a huge impact if China had soybean pricing power. Chinese lack of pricing power in the international soybean market will directly lead to the manipulation of Chinese soybean prices by the international market.

\section{CONCLUSIONS}

China classifies soybean as a food crop, which is different from the international classification of soybeans as oil crops. This shows the dependence of ordinary Chinese consumers on soybeans and the government's emphasis on soybeans. The current problems faced by domestic soybean production, consumption, and trade have led us to raise soybean supply to a strategic level of national food security. Therefore, food security not only has the strategic characteristics of safeguarding national economic security, but also has the strategic characteristics of stabilizing national political security. The realization of the second goal is also highly dependent on good and stable international relations, especially Sino-US relations because today's soybean breeding, production, trade and oil extraction are mainly in the hands of the United States and its multinational companies. This means that once there is a big fluctuation in Sino-US relations, the United States will regain its strategic weapon of food diplomacy. It will be difficult for China to achieve the third goal of soybean supply. China needs to improve the large-scale cultivation of soybeans and reduce the cost of soybean cultivation. Chinese soybean planting costs are higher than those of other major soybean producers in the world. At the same time, small-scale planting requires a large investment in family labor, which affects the enthusiasm of farmers. Therefore, improving the scale of soybean planting is conducive to reducing planting costs and increasing planting enthusiasm. China needs to increase soybean subsidies and gradually establish a stable-complete soybean subsidy mechanism to increase soybean acreage. In general, soybeans have become the weakest link in the national food security chain. The current Sino-US trade friction on the soybean issue has also made us more aware of the importance and urgency of achieving soybean supply security.

\section{REFERENCES}

[1] Qian, H., Engel, B. A., Tian, X., Sun, S., Wu, P., \& Wang, Y. (2020). Evaluating drivers and flow patterns of interprovincial grain virtual water trade in China. Science of the Total Environment, 732. https://doi.org/10.1016/j.scitotenv.2020.139251

[2] Lin, S., Mingxian, Q., \& Reed, M. R. (2018). The effects of soybean trade policies on domestic soybean market in China during the food crisis. China Agricultural Economic Review, CAER-04-2016-0061. https://doi.org/10.1108/CAER-04-2016-0061

[3] Wang, Y., Zhao, J., Fu, J., \& Wei, W. (2019). Effects of the grain for green program on the water ecosystem services in an arid area of China-using the Shiyang River basin as an example. Ecological indicators, 104(SEP.), 659-668. https://doi.org/10.1016/j.ecolind.2019.05.045

[4] Wang, Y., Zhao, J., Fu, J., \& Wei, W. (2019). Effects of the grain for green program on the water ecosystem services in an arid area of China-using the Shiyang River basin as an example. Ecological indicators, 104(SEP.), 659-668. https://doi.org/10.1016/j.ecolind.2019.05.045 
[5] Seal, C. (2017). Perspective: a definition for whole-grain food products-recommendations from the healthgrain forum. Advances in Nutrition, 8(4), 525-531. https://doi.org/10.3945/an.116.014001

[6] Oktyajati, N., Hisjam, M., \& Sutopo, W. (2018). The dynamic simulation model of soybean in Central Java to support food self sufficiency: A supply chain perspective. American Institute of Physics Conference Series. American Institute of Physics Conference Series. https://doi.org/10.1063/1.5024074

[7] Gill, M., Feliciano, D., Macdiarmid, J., \& Smith, P. (2015). The environmental impact of nutrition transition in three case study countries. Food Security, 7(3), 493-504. https://doi.org/10.1007/s12571-015-0453-x

[8] Liu, H., Hussain, S., Zheng, M., Peng, S., Huang, J., \& Cui, K., et al. (2015). Dry direct-seeded rice as an alternative to transplanted-flooded rice in central China. Agronomy for Sustainable Development, 35(1), 285-294. https://doi.org/10.1007/s13593-014-0239-0

[9] Kassie, M., Teklewold, H., Jaleta, M., Marenya, P., \& Erenstein, O. (2015). Understanding the adoption of a portfolio of sustainable intensification practices in eastern and southern Africa. Land Use Policy, 42, 400-411. https://doi.org/10.1016/j.landusepol.2014.08.016

[10] Yuyu, L., Jingjing, G., Linlin, Z., Xin, J.,Yongfei, F., \& Lin, L. (2020). Analysis of agricultural water use efficiency in Shandong province based on DEA and Malmquist model. IOP Conference Series: Earth and Environmental Science, 585(1), 012090 (6pp). https://doi.org/10.1088/1755-1315/585/1/012090

[11] Guo, J., Mao, K., Zhao, Y., Lu, Z., \& Xiaoping, L. (2019). Impact of climate on food security in mainland China: a new perspective based on characteristics of major agricultural natural disasters and grain loss. Sustainability, 11(3). https://doi.org/10.3390/su11030869

[12] Wang, N., Gao, Y., Li, X., \& Wang, Y. (2018). Efficiency analysis of grain production inputs: utilization in China from an agricultural sustainability perspective. Agricultural Research. https://doi.org/10.1007/s40003-018-0293-y

[13] Wichelns, D. (2015). Water productivity and food security: considering more carefully the farm-level perspective. Food Security, 7(2), 247-260. https://doi.org/10.1007/s12571-015-0426-0

[14] Zanten, H. H. E. V., Mollenhorst, H., Klootwijk, C. W., Middelaar, C. E. V., \& Boer, I. J. M. D. (2016). Global food supply: land use efficiency of livestock systems. The International Journal of Life Cycle Assessment, 21(5), 747758. https://doi.org/10.1007/s11367-015-0944-1

\section{Contact information:}

\section{Jianting FU}

(Corresponding author)

College of Economics \& Management,

Huazhong Agricultural University,

Wuhan, 430070, Hu Bei, China

E-mail: fujianting_hzau@163.com

\section{Dan LYU}

College of Economics \& Management, Huazhong Agricultural University,

Wuhan, 430070, Hu Bei, China

\section{Jian SUN}

College of Economics \& Management, Huazhong Agricultural University,

Wuhan, 430070, Hu Bei, China 